\title{
Filiação Adotiva por Pares Homoafetivos: Um Estudo do Processo e Significados para Famílias Protagonistas
}

\author{
Missilene Menezes Mota \\ Marlizete Maldonado Vargas* \\ Centro Universitário Tiradentes (UNIT), Aracaju, SE, Brasil \\ Tatiana Torres de Vasconcelos \\ Universidade Federal de Sergipe, Aracaju, SE, Brasil
}

\begin{abstract}
RESUMO
O presente trabalho objetivou conhecer o processo de adoção em famílias brasileiras homoafetivas cuja prole foi advinda da adoção legal. A pesquisa qualitativa foi desenvolvida por meio de depoimentos de pares homoafetivos, enviados pela internet, a partir de algumas questões disparadoras. Foram selecionadas para este estudo quatro famílias que atenderam aos critérios de inclusão e exclusão, calcados nos objetivos. Quanto aos resultados, apenas em uma delas os parceiros conseguiram adotar de forma conjunta. No que se refere ao perfil da criança desejada, observou-se bastante flexibilidade em relação ao sexo, idade e cor. A convivência inicial foi marcada por dificuldades de adaptação, porém na atualidade é significada como num estágio de superação das dificuldades. As trocas de ensinamentos e a aceitação da autoridade dos pais ocorreram simultaneamente ao estabelecimento e fortalecimento dos vínculos afetivos. Conclui-se que os sujeitos passaram por um processo de adaptação familiar semelhante ao já verificado em outros estudos sobre adoção de crianças maiores e que a orientação sexual dos pais exerceu pouca influência no processo de formação das famílias.
\end{abstract}

Palavras-chave: adoção; famílias homoafetivas; ambiente social.

\begin{abstract}
Adoptive by Homosexual Couples: Study of the Process and Meaning for Families Players

Changes in marital ties and parenthood have triggered new and emerging family structures, such as homosexual families with adopted children. This body of work seeks to understand the development process of Brazilian families composed by homosexual parents with adoptive children. A qualitative research was collected through testimonials of homosexual couples over the Internet - they were each provided with a thorough guide. Four families were chosen which fit each and every criteria of inclusion and exclusion as being homosexual couples with established relationships seeking legal adoption. Of the four homosexual couples chosen, only one successfully adopted a child by both partners, representing $1 / 4$ of this adoption case carried out in the whole country. There was a flexibility regarding the profile of the desired child to be adopted. Acquaintanceship was established through terms converging in the difficulties of the whole family's adaptation process. Nowadays, the relationship is established overcoming the initial adversities. The exchange of experiences and parent authority perception happen simultaneously as ties of affection strengthen. It establishes that the adoption process in these families presents similar aspects to the traditional adoption tardive. Parents' sexual orientation had little or no relevant influence on the children. It is more relevant to the families' environment social prejudice and juridical questions and issues than pedagogical ones.
\end{abstract}

Keywords: adoption; homosexual family; involved process; social environment.

Os modelos familiares e os vínculos matrimoniais passaram por mudanças gradativas que possibilitaram a união consensual, pois o divórcio se tornou uma alternativa para que os indivíduos não permaneçam

* Endereço para correspondência: Marlizete Maldonado Vargas - mmv.caju@gmail.com 
em um matrimônio vitalício e as relações entre homens e mulheres começam a ser simétricas, em que sexo e procriação não estão mais atrelados (Freixa, 1998). Dentre as modificações na estrutura familiar se percebe o aparecimento mais frequente de famílias monoparentais (com somente um dos pais), pluriparentais ou reconstituídas (onde casais em novas uniões mantêm uma relação materno/parental com a prole do parceiro), famílias homoafetivas, famílias sem filhos e famílias que não possuem vínculo legal (Fleck \& Wagner, 2003). No presente trabalho será priorizada a família homoafetiva.

Um dos mitos mais presentes em relação às famílias homoafetivas é o de que as crianças que se desenvolvem nesse tipo de configuração terão a mesma orientação sexual de seus pais (Matias, 2007). Essa conclusão equivocada foi refutada nos estudos de Bailey, Bobrow, Wofe e Mikach (1995) e Golombok e Tasker (1996), que afirmaram que a maioria dos filhos de pares homoafetivos apresenta uma orientação heteroafetiva.

Outro problema enfrentado pelas famílias homoafetivas se relaciona ao silêncio constitucional pela ausência de elaboração legislativa sobre a união e a adoção, além de certo conservadorismo judicial. A omissão legal está relacionada ao fato dos pares homoafetivos não possuírem plena aceitação social, o que repercute nos legisladores, eleitos pela sociedade (Spengler, 2008).

A coparentalidade ou a adoção por um segundo pai ou mãe guarda o direito da criança a manter uma relação continuada com ambos os pais/mães homoafeti-

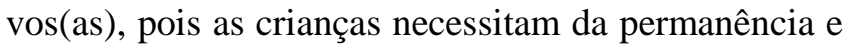
da segurança proporcionada pelo fato de ter dois pais ou duas mães, com todos os direitos legais. Desconsiderar o status legal da adoção a ambos os pais ou mães, impede que o/a filho(a) adotivo(a) desfrute da segurança psicológica e legal que provem de dois pais ou mães capazes e carinhosos, pois as crianças com pais ou mães homoafetivas podem ter as mesmas necessidades para uma vida saudável, o ajuste e o desenvolvimento que as crianças de pais heteroafetivos (Academia Americana de Pediatria, 2002).

Autores têm pontuado que a educação oferecida por pares homoafetivos não diferencia ao ponto de influenciar seus filhos, quer seja na orientação sexual ou estruturação da identidade pessoal, quer seja na autoestima, sociabilidade ou transtornos de qualquer ordem (Brooks \& Goldberg, 2001; Naranjo, Hernandez, Oliver \& Chacón, 2004; Patterson, 2006). Outros autores também observaram que, em relação à função paternal, não há diferenças substanciais entre os pais homoafetivos e heteroafetivos (Fernández \& Vilar, 2004, Short, Riggs, Perlesz, Brown \& Kane, 2007).

Diante do exposto, esta pesquisa teve como objetivo geral conhecer o processo de adoção em famílias brasileiras homoafetivas, cuja prole foi advinda da adoção legal. Especificamente, objetivou-se discutir as facilidades e entraves sócio-jurídicos no processo de adoção por pares homoafetivos; as questões envolvidas no processo de vinculação criança-família na adoção homoafetiva; e o papel dos contextos sociais presentes desde a decisão pela adoção até a convivência atual.

\section{MÉTODO}

Trata-se de uma pesquisa qualitativa, de caráter Etnográfico Virtual, pela imersão do pesquisador na realidade experienciada por um determinado grupo, que utiliza como veículo de comunicação o computador (Hine, 2000). Através deste método os dados virtuais foram coletados via internet, pois a Etnografia Virtual ou Netnografia foi oriunda da Antropologia que reúne técnicas que auxiliam o pesquisador no trabalho de observação, a partir da inserção em comunidades para pesquisa, para o contato intra-subjetivo com o objeto de estudo (Geertz, 2001). A Etnografia Virtual possibilita que o pesquisador submerja no mundo pretendido ao estudo, por um tempo determinado, e tenha conhecimento das relações dos protagonistas que participam dos processos sociais; com objetivo de dar sentido às pessoas, quer esse sentido seja por suposição ou pela maneira implícita em que as próprias pessoas dão sentido às suas vidas (Hine, 2000).

Como critérios de inclusão das famílias-sujeitos estabeleceu-se que os pares homoafetivos deveriam ter uma união estável com coabitação e o processo de adoção estar tramitando ou já deferido pelo judiciário. Como critérios de exclusão, foram estabelecidos: negação de identificação dos sujeitos (via e-mail) para a pesquisadora que levantou os dados, a não aceitação do Termo de Consentimento Livre e Esclarecido enviado por e-mail, e a desistência da participação.

Utilizou-se um roteiro com ítens disparadores para levantar as categorias de análise: o tempo de relação 
do par homoafetivo, a decisão pela adoção, a escolha da criança, os trâmites jurídicos, o início da convivência e a convivência atual com a criança. Assim, foram incentivados os depoimentos livres e informações específicas de cada grupo sujeito.

Em relação à escolha da(s) criança(s), solicitaram-se informações quanto à preferência em termos de idade, gênero e/ou cor da pele. Quanto aos procedimentos relacionados aos trâmites jurídicos, pediu-se que relatassem o processo desde o cadastro de pretendente(s) à adoção, até o momento em que foi deferida a guarda, para fins de adoção da(s) criança(s). Dentro da questão 'início da convivência', abordou-se como foi a chegada do(s) filho(s); como foram estabelecidos os primeiros vínculos, e se houve mudanças significativas na rotina do par. Em relação à convivência atual, solicitou-se um relato sobre as mudanças observadas nos comportamentos e na rotina desde o início da convivência e como consideram o estabelecimento do vínculo entre criança- família, e que expusessem sobre possíveis barreiras para a adoção.

Após a aprovação do projeto pelo Comitê de Ética em Pesquisa, sob o registro 081109, buscaram-se através do portal da Associação Nacional de Grupos de Apoio à Adoção (ANGAAD), dentre os setenta e cinco sites brasileiros cadastrados, os sites ativos dos grupos de apoio à adoção. Posteriormente, foram enviadas mensagens para todos os sites e emails dos grupos em atividade, com a divulgação do blog Adoção por Casais Homoafetivos. Alguns grupos repassaram o e-mail da pesquisadora responsável pela coleta para os sujeitos de suas malas diretas, informando sobre a pesquisa e incentivando depoimentos no blog e/ou e-mail da pesquisadora.

O blog foi elaborado com o objetivo de ser uma ferramenta de captação unificada dos depoimentos dos pares homoafetivos e também para contribuir na troca e discussão de informações sobre a adoção homoafetiva. Assim, a técnica utilizada foi a estimulação via blog com solicitação do depósito de depoimentos dos voluntários. Posteriormente, solicitou-se contato via e-mail das famílias-sujeitos enquadradas nos critérios de inclusão. O e-mail da pesquisadora responsável também serviu de via para encaminhar o Termo de Consentimento Livre e Esclarecido para os voluntários garantindo o anonimato dos sujeitos e reforçando a importância da veracidade dos dados. Após o recebimento do documento assinado pelos participantes da pesquisa, o roteiro com os itens disparadores foi encaminhado e as respostas enviadas para o e-mail da pesquisadora.

Para análise dos dados utilizou-se a Rede de Significações-RedSig (Rossetti-Ferreira, Amorim, Silva \& Carvalho, 2004). Esta análise prioriza conhecer o desenvolvimento das interações que os indivíduos estabelecem através da afetividade, linguagem e cognição com as práticas sociais em geral, e de que modo esses dados se relacionam ou se contrapõem aos de outras pesquisas.

\section{RESULTADOS E DISCUSSÃO}

Foram sujeitos da pesquisa quatro famílias de pares homoafetivos, que residem em pontos diferentes do Brasil (São Paulo, Pernambuco, Rio de Janeiro e Mato Grosso). O indivíduo mais novo tem trinta anos e o mais velho cinquenta e sete, sendo a média das idades de trinta e oito anos. A caracterização dos pares homoafetivos participantes da pesquisa está disposta no Quadro 1. Para este quadro não foi determinada a RedSig, já que por meio deste método podem ser delineadas as relações que ocorrem nos diversos círculos de relações dos indivíduos.

Quadro 1: Caracterização dos aspectos referentes à família e à adoção

\begin{tabular}{|l|l|l|l|}
\multicolumn{1}{|c|}{ Sujeitos* } & \multicolumn{1}{c|}{ Estrutura Familiar } & Tempo de Relação & \multicolumn{1}{c|}{ Tipo de Adoção } \\
\hline F1 - Mateus e Luis & 2 homens e 2 meninas & 5 anos & Adoção pelo par \\
\hline F2 - Jessica e Mara & 2 mulheres e 1 menino & 21 anos & Monoparental \\
\hline F3 - Lana e Bruna & 2 mulheres e 1 menina & 15 anos & Monoparental \\
\hline F4 - Amanda e Regina & 2 mulheres, 1 menina e 1 menino & 3 anos & Monoparental \\
\hline
\end{tabular}

* Nomes fictícios para preservar a identidade dos sujeitos

Apenas uma das famílias pesquisadas é de homoafetivos masculinos (F1), Mateus e Luis. Esse casal possui cinco anos de relação estável, adotou legalmente e em conjunto duas meninas com idades de cinco e 
sete anos. As outras famílias também adotaram legalmente, porém por apenas um dos componentes do par. Jessica e Mara adotaram um menino com idade de sete anos (F2); Lana e Bruna são mães de uma menina de seis anos (F3) e Amanda e Regina adotaram duas crianças, uma menina de três e um menino de dois anos (F4). O tempo de união destas famílias foi respectivamente 21,15 e 3 anos.

A adoção apresenta, dentre as várias motivações para sua consecução, o sentimento de completude da família, quando ocorre a inserção da criança no ambiente familiar. No entanto, a formação da família já se estabelece quando dois indivíduos se escolhem e se unem, iniciando o processo de aquisição de bens materiais e amadurecimento da relação no cotidiano (Cerveny \& Berthoud, 2002).

Os pares homoafetivos que desejam constituir prole podem utilizar a adoção ou a procriação por parte de um dos membros do par. Nesta pesquisa os pares participantes optaram pela adoção, sem outros tipos de tentativas anteriores. Segundo Spengler (2008), a ausência de uma lei que assegure a todos os pares homoafetivos a adoção conjunta está baseada na pouca aceitação social que este tipo de estrutura familiar minoritária ainda possui.

Com base no Quadro 1, constata-se o maior número de pares homoafetivos do gênero feminino. Resultados similares também foram observados na pesquisa de Ebrahim (2001) que, embora não tratando de famílias homoafetivas, apontou que $25,9 \%$ das mulheres solteiras preferiram a adoção por crianças maiores de dois anos à de bebês $(6,1 \%)$. $\mathrm{O}$ fato da maior procura pela adoção partir da mulher pode ser explicado com base nas funções familiares culturalmente arraigadas. A maternagem, após várias gerações e modificações na estrutura familiar, ainda é uma função exercida pela mulher. Mota e Vargas (2010) pontuaram que os papéis familiares das mulheres de classe média aracajuana que exercem profissões fora do lar, como o cuidado com a educação escolar e social dos filhos, são cumulativos e não compartilhados com a figura paterna. Esses dados podem ser relacionados com a Teoria do Apego de Bowlby (1982), que enfatiza a importância do relacionamento entre a mãe (ou substituta) e o bebê, como valor de sobrevivência pelos cuidados que este necessita.

Por outro lado, conforme aponta Ferrari (2011), a necessidade dos homens serem incluídos na relação de cuidados com o bebê já podia ser observada em tribos indígenas. $\mathrm{O}$ autor cita a síndrome de Couvad $^{1}$ como representativa dessa necessidade que era respeitada pela tribo, mas que não aparece nas línguas espanhola e portuguesa, denotando a força cultural trazida pelos europeus que instituíram posteriormente o mito do "amor materno", que coloca a maternagem como uma condição instintiva de cuidados exercidos pelas mulheres (Badinter, 1985).

A Rede de Significações que se estabeleceu no processo de escolha da criança para a adoção é composta pelo pai e mãe no nível individual; pelas relações se estabeleceram entre pai-pai, mãe-mãe, por funcionários das Varas da Infância e Juventude (VIJ); e o cenário são o ambiente familiar onde ocorreram as tomadas de decisão sobre a adoção; e a VIJ onde os adotantes se cadastraram para serem habilitados para o processo de adoção.

Quadro 2: Decisão pela adoção e a escolha da criança

\begin{tabular}{|l|c|l|}
\multicolumn{1}{|c|}{ Escolha da Criança } & Decisão de Adotar & \multicolumn{1}{c|}{ Sujeitos } \\
\hline $\begin{array}{l}\text { Sem preferência por gênero e idade } \\
\text { Sem preferência por gênero, idade superior a dois anos e } \\
\text { sem doença incurável ou deficiência }\end{array}$ & Ambos & $\begin{array}{l}\text { F1 - Mateus e Luis } \\
\text { F4 - Amanda e Regina }\end{array}$ \\
\hline Sem escolha a priori e depois encantamento por um menino & Jessica & F2 - Jessica e Mara \\
\hline Menina negra, entre dois e cinco anos & Lana & F3 - Lana e Bruna \\
\hline
\end{tabular}

Encontrou-se em duas famílias o desejo da maternagem como parte de um objetivo do par e em outras duas famílias com a ocorrência do desejo da maternagem em uma das companheiras. Em relação às carac- terísticas das crianças, três famílias não delinearam exigências em relação à idade, cor e sexo; e uma optou por criança afrodescendente, do sexo feminino, com até cinco anos. Uma das famílias colocou como 
restrição para adoção apenas o diagnóstico de doença incurável ou deficiência da criança, como se pode observar nas seguintes falas:

Queríamos uma menina, pois sempre quis menina e não podia ser bebê, pois não tenho paciência com pequeninos, decidimos que seria uma menina negra, com idade entre 2 e 5 anos. (Lana e Bruna)

Então a escolha de até dois irmãos, independente do sexo e todas aquelas outras milhares de coisas que temos que escolher, como se eles poderiam ser filhos de usuários de substâncias psicoativas. Só optamos por não escolher crianças que tivessem doenças incuráveis ou que fossem deficientes, pois não disporíamos de tempo suficiente para cuidados especiais e integrais. (Amanda e Regina)

Conforme foi levantado, em relação ao cenário onde ocorreu a adoção, todos os pares buscaram as Varas Cíveis ou específicas de Infância e Juventude de suas cidades para iniciar o processo de cadastro para adoção, sendo que este foi concluído quando os pretendentes à adoção traçaram o perfil da criança que pretendiam adotar. O primeiro passo para pleitear uma adoção de uma criança ou adolescente é o deferimento do processo de habilitação para adoção. Segundo o Cadastro Nacional de Adoção (CNA) (2008), os indivíduos que pretenderem adotar precisam habilitar-se em uma Vara Cível da Infância e da Juventude de sua comarca. Quando houver o deferimento do processo, o perfil do indivíduo adotante será cruzado para encontrar as crianças e os adolescentes que possuam um perfil aproximado do que se procura.

Observou-se, nesta pesquisa, que os pares homoafetivos não parecem apresentar um perfil excludente para a escolha do filho, e não raro optam pela adoção de crianças que costumam não ser o foco da maioria dos casais heteroafetivos. Estes dados corroboram aqueles relatados na pesquisa de Weber (2003), que apontou que os adotantes heteroafetivos procuram bebês saudáveis, brancos, do sexo feminino e recémnascidos. Assim, crianças mais velhas permanecem nos abrigos por possuírem características menos desejadas, além das portadoras de alguma deficiência física e/ou mental, ou negra (Almeida, 2003; Cassin, 2000; Mariano \& Rossetti-Ferreira, 2008; Vargas, 1998).

O processo de adoção, e a consequente escolha da criança, por casais heteroafetivos, parecem ser pautados na reprodução dos modelos de paternidade e ma- ternidade biológicos, de modo que, frequentemente, as características físicas da criança constituem um fator de elevada relevância para a adoção (Andrade, Costa \& Rossetti-Ferreira, 2006; Naranjo et al., 2004). Assim, o processo de adoção acaba por se alicerçar em um perfil excludente, em que, historicamente, vêm sendo priorizadas as crianças do gênero feminino, brancas, entre zero e dois anos de idade (Andrade et al., 2006; Weber, 2003). Desta forma, os critérios seletivos em relação à cor, à idade e ao gênero seriam elementos determinantes para a escolha do filho adotivo por casais heteroafetivos, e o perfil excludente usualmente demandado por tais casais poderia, inclusive, justificar a permanência de algumas crianças e adolescentes nas instituições de proteção, conforme discutido por Amim e Menandro (2007).

Atualmente se vivencia uma nova cultura da adoção atribuindo novos sentidos ao ser pai e mãe. A partir dessa perspectiva busca-se uma família para uma criança e não o inverso, fomentando adoções diferenciadas, como por exemplo, as adoções tardias, de grupos de irmãos, de crianças com necessidades especiais, portadoras do vírus HIV e as adoções interraciais (Costa \& Rossetti-Ferreira, 2007). Assim, a adoção vem assumindo o seu mais profundo e completo significado de proteção às crianças e adolescentes impossibilitados de crescer no seio de sua família de origem (Freire, 2001).

Em relação ao processo de adaptação das crianças nas famílias, foram encontrados pontos de convergência com a primeira pesquisa sobre adoção tardia no Brasil, realizada por Vargas (1998), que são: a dificuldade de acesso aos indivíduos para participar da pesquisa, devido ao pequeno número de adotantes homoafetivos no país; o enfrentamento do preconceito social, principalmente pela questão da formação familiar se constituir de forma heterogênea e fora dos padrões culturalmente aceitos; necessidade de preparação e acompanhamento específico durante o processo, principalmente devido aos comportamentos que costumam aparecer no início do processo de adaptação, conforme levantado pela autora supracitada: comportamento agressivo e ritmo de desenvolvimento global acelerado.

O cenário onde se desenrolaram os trâmites jurídicos continua sendo a VIJ, como no quadro 2, pois com o deferimento do processo de adoção, os pais e as mães puderam visitar a criança no abrigo, realizar as saídas de finais de semana, conseguir a guarda e a 
adoção. As relações configuradas na Redsig são compostas pelas díades pai-pai, mãe-mãe, pai-filho(s), mãe-filho(s), e irmãos. Vale destacar que as configurações do nível individual e interativo da rede são as mesmas durante os trâmites jurídicos, início da convivência e convivência atual.

As famílias homoafetivas participantes desta pesquisa foram unânimes em definir os trâmites jurídicos como um processo sequencial, que se inicia com o cadastro na VIJ e a entrega da documentação; a inserção em grupos de apoio, importante para discutir sobre a adoção e aprender com a experiência de quem já adotou; ser apresentados à(s) criança(s) que, segundo a equipe técnica, melhor se encaixa(m) no perfil dos adotantes; fazer as visitas aos "abrigos" (instituições de acolhimento) e depois conviver durante finais de semana, como um processo gradativo de inserção da criança no ambiente familiar.

A guarda é um momento bastante esperado, pois é quando se inicia, de fato, a adaptação da criança. $\mathrm{O}$ deferimento do processo legal de adoção ocorreu em momentos diferentes para cada família, pois a duração do estágio de convivência pode variar a critério de cada juiz ou comarca conforme apontado por Vargas (1998). Os extratos dos depoimentos dos pares homoafetivos descritos a seguir exemplificam o processo de deferimento de guarda para fins de adoção:

O processo via decisão judicial foi tranquilo [...], a juíza [...] numa conversa informal, coletou tudo que necessitava sobre mim e os meus de uma forma não invasiva e respeitosa. (Jessica e Mara)
Foi só um passo para as visitas formais, depois para as saídas de final de semana e então mais um pulo para a guarda. Agora estão conosco há quase dois meses e vamos pedir sua adoção definitiva. (Mateus e Luis)

Com o Estatuto da Criança e do Adolescente (ECA, Lei 8.069/90), a adoção é deferida se houver benefícios para as crianças e adolescentes que estão em instituições de proteção, restando aos adultos requerentes serem respeitados na solicitação junto ao órgão judiciário (Fernández \& Vilar, 2004).

Outro ponto importante a favor das crianças e dos adolescentes residentes em instituições de proteção foi o destaque para o caráter provisório da medida prevista na Lei Nacional da Adoção (Lei 12.010, de 3 de agosto de 2009), que reza no seu artigo 19 que as crianças e adolescentes não podem permanecer por um período maior que dois anos em programa de acolhimento institucional, salvo necessidade devidamente fundamentada pela autoridade judiciária; e a cada seis meses, relatórios psicossociais devem ser produzidos, atestando as possibilidades de reintegração ou colocação em família substituta. As crianças e adolescentes aptas para adoção devem ser incluídas no Cadastro Nacional de Adoção, e atualização do mesmo (Agência Senado, 2009).

No Quadro 3 o cenário é o ambiente familiar, onde as relações afetivas e sociais entre os membros da família se estreitam.

Quadro 3: Temas definidores da adaptação familiar homoafetiva

\begin{tabular}{|l|l|}
\hline Descrição do Início da Convivência & Sujeitos \\
\hline $\begin{array}{l}\text { Dificuldade por não saber cuidar das filhas } \\
\text { Dificuldade na identificação das necessidades da filha }\end{array}$ & $\begin{array}{l}\text { F1 - Mateus e Luis } \\
\text { F3 - Lana e Bruna }\end{array}$ \\
\hline Desesperadora por não saber manejar os comportamentos do filho & F2 - Jessica e Mara \\
\hline Maravilhoso, trabalhoso para reorganizar as tarefas familiares e laborais & F4 - Amanda e Regina \\
\hline
\end{tabular}

Com o ingresso do filho no ambiente familiar, os adotantes precisaram modificar suas rotinas e se adaptar à nova convivência. As quatro famílias que adotaram se posicionaram sobre essa questão de formas diversas, o que pode ser sintetizado como "Difícil", "Desesperadora" ou "Maravilhosa". Percebeu-se que a palavra dificuldade foi a que mais apa- receu. No entanto, ela está inserida de modo subjetivo nas outras respostas, pois quando Jessica e Mara apresentaram a sua convivência inicial como "Desesperadora", percebe-se a dificuldade em manejar as necessidades essenciais da criança; já Amanda e Regina apresentaram a dificuldade na modificação da rotina de trabalho e familiar para conciliar com os 
cuidados dos filhos, mas também considera essa modificação como maravilhosa.

Meu filho não tinha educação social, doméstica e nenhum limite, além de forte tendência de se colocar em risco sério, pois ele dava chutes em mesa de tampo de vidros, no tampo de vidro, socos no espelho, se pendurava na grade e a sacudia, se escondia embaixo dos carros no estacionamento. (Jessica e Mara)

[...]. Eu [Amanda] alterei meus horários para que pudesse trabalhar à tarde e à noite para que de manhã pudesse ficar em casa com eles e com a minha funcionária, levar ao médico, natação, enfim, tudo que fosse necessário neste período, até para não atrapalhar a escolinha. Regina dispensou os alunos do período noturno para que pudesse buscar as crianças na escola e ficar com elas a noite toda, pois estou sempre na universidade. (Amanda e Regina)

Frente às dificuldades biológicas (alimentação, banho) e psicológicas que as famílias homoafetivas tiveram em relação aos seus respectivos filhos, a alternativa encontrada foi obtida por meio do suporte das famílias extensas, que apoiaram o processo de adoção e auxiliaram na adaptação familiar para conciliar a rotina familiar com o trabalho e os cuidados das crianças. Em relação às tarefas de maternagem, Ferrari (1999) afirma que os cuidados com as crianças devem ser executados pelos dois cuidadores, havendo o direcionamento das tarefas segundo os gostos e as facilidades que cada indivíduo tenha, e sempre com igualdade de tarefas, pois o autor supracitado desconsidera a existência de atividade estritamente feminina. Como se pode encontrar no Quadro 1 desta pesquisa, um par homoafetivo masculino adotou duas meninas e cumpre com os cuidados biológicos e psicológicos das filhas.

Em relação à família de Jessica e Mara, o comportamento agressivo do filho teve início após a adoção. Segundo Vargas (1998), a agressividade está relacionada ao processo de adaptação da criança à nova família, através do estreitamento dos vínculos afetivos. Assim, os pais precisam ser flexíveis para compreender e manejar as necessidades dos filhos.

Em relação às dificuldades relacionadas à convivência inicial dos membros das famílias, não foram encontradas pesquisas que apontassem esta questão. Por outro lado, Ebrahim (2001), em sua pesquisa, afirma que a dificuldade de educar uma criança ou adolescente institucionalizado seria um dos motivos para os adotantes não buscarem a adoção tardia, pois é senso comum que as crianças teriam dificuldade para aceitar novos padrões estabelecidos pelos pais. Outro ponto encontrado em diversos autores (Andrade et al., 2006; Brauer, 1993; Brodzinsky, Smith \& Brodzinsky, 1998; Turcatto, 2002) é a dificuldade em lidar com a questão das origens da criança, apesar de ser sabido que a não revelação pode gerar problemas emocionais ao adotado.

No Quadro 4 a RedSig tem como cenários de convivência o ambiente familiar, a escola de educação sistemática e a escola de natação.

Quadro 4: Temas definidores da convivência atual

Descrição da Convivência Atual

Troca de ensinamentos

Percepção da autoridade

Estreitamento dos vínculos afetivos

Estreitamento dos vínculos afetivos
Sujeitos Cenários Atuais da Convivência

Família, escola e escola de natação

Família

Família e escola

Família, escola e aula de natação
Nesta categoria dois pares referenciaram a convivência atual como o estreitamento dos vínculos afetivos, pois a relação com a criança evoluiu até ela conseguir confiar nas mães e se sentirem integrantes relacional e afetivamente da família. Uma família citou a troca de ensinamento, que pode estar relacionada com a vida escolar das crianças, pois as escolas executam o projeto de ensinar às crianças a maneira de cuidar do meio ambiente, por exemplo. Assim, as crianças podem estar ensinando aos pais a aprendizagem adquirida e os pais podem estar inserindo novos aprendizados para as filhas.

Apenas uma família homoafetiva fez referência à percepção da autoridade das mães, como pode ser 
encontrada no quadro 4 , pois uma criança tinha forte tendência de se colocar em risco de morte ou acidente grave. Estes comportamentos extinguiram-se após a internalização da figura das mães como responsável que dão limites, mas também que proporcionam afeto.

Assim, de modo geral, os pares percebem a convivência como uma troca de hábitos saudáveis, afetivos e morais entre os componentes da família, com o reconhecimento dos papéis que cada membro desempenha e o aprimoramento da confiança da criança em relação aos novos pais, que lhe proporcionam cuidados e proteção.

Sabemos que estamos ensinando muito (hábitos de higiene e bons hábitos morais), mas estamos aprendendo muito. Sabemos que não só nossas filhas estão crescendo, pois também estamos crescendo muito. (Mateus e Luis)

Hoje, me percebe e respeita de fato como mãe e reconhece as olhadas que dou quando está fazendo besteira e imediatamente para. (Jessica e Mara)

Kátia quando chegou não falava nada, apenas chorava e fazia sim e não com a cabeça. Hoje ela pronuncia várias palavras que entendemos e milhares que não fazemos a mínima idéia do que se trata; Já Bernardo, talvez por ser menor, entendemos que se adaptou com muito mais facilidade e já reconhece em nós como um porto seguro, a palavra que dá amor, carinho, afetividade, mas também que impõe limites. Os dois, no início, brincavam separados e quase não se "enxergavam" como irmãos. Hoje as brincadeiras são em conjunto, vimos muitas vezes ao dia demonstrações de carinho e cuidado um pelo outro. (Amanda e Regina)

A Lei Nacional de Adoção preconiza a obrigatoriedade do acompanhamento multidisciplinar para a criança e o adolescente desde o período de acolhimento institucional até a inserção em uma nova família, de modo a favorecer a adaptação de pais e filhos, pois os adotantes estão em processo de aprendizagem para cuidar, proteger e identificar as necessidades dos filhos; e os filhos assimilam o reconhecimento dos pais como uma figura de autoridade, que impõe limite (Agência Senado, 2009).

Para que os membros das famílias se adaptassem aos novos papéis, um processo de amadurecimento biopsicossocial ocorreu, tendo em vista que as crianças residiam em abrigos, e não diferente de qualquer outra organização, os indivíduos que compõem o qua- dro de trabalhadores possuem horários de atendimento e funções delimitadas a serem cumpridas. Assim, a vinculação afetiva das crianças abrigadas com os funcionários costuma ser distante. O tempo em que permaneceram abrigados é um importante fator a ser considerado no processo de vinculação na adoção. Geralmente, as crianças necessitam de estimulação por estarem em fase de crescimento e terem tido laços afetivos frágeis, rompidos, e muitas vezes não terem a oportunidade de elaboração dos lutos ante as perdas sofridas (Vargas, 2006; Weber \& Kossobuski, 1993).

De acordo com o demonstrado no Quadro 1, dentre as crianças adotadas houve casos de crianças maiores de dois anos e grupos de irmãos. As características da adoção por pares homoafetivos estão relacionadas com as já estudadas dos processos de adaptação criança-família na adoção de crianças maiores. Conforme alguns autores como Ebrahin (2001) e Berthoud (2002), o ambiente familiar saudável contribui para que a criança desenvolva condições de apego seguro, favorecendo também o seu equilíbrio emocional quando vivenciar situações frustrantes (Sarriera, Silva, Kabbas \& Lópes, 2001). Para que o vínculo criançafamília seja bem estabelecido é primordial que as necessidades biológicas e afetivas sejam atendidas de acordo com as necessidades do adotivo. Assim, pode-se destacar a importância para a criança se sentir-se segura dentro da nova família e ter a garantia de que não será abandonada, mas de pertencer ao novo grupo familiar.

E, conforme os vínculos familiares se desenvolvem, a família fará o papel de facilitador na inserção da criança no ambiente social (Bee, 2003). Assim, a inserção das crianças não somente em instituições de ensino regular, mas em outras atividades como a natação contribuiu, segundo os participantes dessa pesquisa, na ressocialização das mesmas. A natação, além de contribuir no desenvolvimento neuropsicomotor e de rotinas disciplinares (Venditti Jr \& Santiago, 2008), através das novas relações afetivas e de autoridade, a criança demonstrava para os pais adotivos suas preferências por amizades e brincadeiras.

Percebe-se que esta pesquisa ratifica as pesquisas de Brooks e Goldberg (2001), Naranjo et al. (2004) e Patterson (2006), quando afirmam serem os pares homoafetivos tão capazes quanto os heteroafetivos de exercer a parentalidade, porém para que o ato de adotar seja levado em consideração, fatores como o me- 
lhor interesse para a criança e o desejo em constituir prole devem ser tratados como prioridades pelo poder público e pela população. Reforçando o que afirma
Martínez (2010), os laços afetivos são construídos com base no processo de vinculação entre os membros da família.

\begin{tabular}{|c|c|}
\hline Barreiras Sociais & Sujeitos \\
\hline Sem referência sobre o assunto & F1 - Mateus e Luis \\
\hline Preconceito da equipe técnica & F2 - Jessica e Mara \\
\hline Protocolo apenas no nome de um indivíduo & $\begin{array}{l}\text { F3 - Lana e Bruna } \\
\text { F4 - Amanda e Regina }\end{array}$ \\
\hline
\end{tabular}

As barreiras sociais retratam as dificuldades ocorridas em algum ambiente social, tendo como protagonistas a família adotiva e indivíduos não vinculados a ela. Mateus e Luis são os únicos que não se reportam ao assunto, já que conseguiram a adoção conjunta; diferente dos pares Lana e Bruna e Amanda e Regina que apontaram como cristalização social o protocolo para adoção vir apenas com o registro de um dos cuidadores. Jessica e Mara referiram que o preconceito que sofreram por membros da equipe técnica do judiciário, reflete, além de uma barreira social, um despreparo destes profissionais.

[...]. Pude ver claramente o despreparo dos 'técnicos' [...]. $O$ assunto homoafetividade nunca foi tocado diretamente. $O$ assistente social quando aqui esteve perguntou quem morava na casa, eu informei: um que eu estava montando para a criança por vir e o outro com uma cama de casal. São 3 quartos, 4 pessoas, 2 com habitantes definidos, eu percebi que ele ficou sem graça quando informei que o quarto era meu e de Mara, mudando logo de assunto, me perguntando se aqui faltava muita água. Não vi pertinência, mesmo porque se meu objetivo era colocar a criança para carregar água, não diria ao assistente social. (Jessica e Mara)

A habilitação foi protocolada apenas no meu nome, pois não aceitam o pedido no nome das duas, mas todas as entrevistas com a equipe de psicólogos e assistentes sociais foram realizadas com ambas. Inclusive na sentença de mérito faz-se referência à Regina que estaria ela tão apta à maternagem quanto eu. (Amanda e Regina)

Segundo apontam Campos e Costa (2004), a família adotiva em processo de cadastramento sofre frente à busca "pela aceitação de suas deficiências ou dificuldades (incompetências)" que podem impedir naquele momento sucesso da adoção (p. 101). As auto- ras ressaltam que, como aspectos subjetivos e/ou as construções sociais acerca do tema estão presentes e podem interferir na avaliação psicossocial dos postulantes à adoção, a formação de grupos de preparação com várias famílias, numa perspectiva de trabalho de grupal multifamiliar, apresenta-se como uma possibilidade de co-construção de saberes. Assim, a horizontalização das relações exerce papel fundamental para o processo de preparação das famílias e enfrentamento de barreiras sociais.

O maior problema enfrentado pelos pares homoafetivos é o silêncio constitucional pela ausência de elaboração legislativa sobre família e adoção homoparental conjunta, além de certo conservadorismo judicial. Sobre isso, Uziel (2007) destaca que a adoção por pais gays ainda é considerada pelo Judiciário como o mal menor, ao invés de se afirmar os ganhos da inserção da criança em uma família.

A sociedade é composta de valores culturais e sistema de exclusões baseados em preconceitos e estigmas. Nas últimas décadas, as questões referentes à sexualidade sofreram mudanças na forma de serem percebidas, ocorrendo maior tolerância com a união entre homoafetivos, mas a contemporaneidade continua sendo marcada pelos estigmas, preconceitos e discriminações aos indivíduos que não têm preferências sexuais dentro de determinados padrões de estrita moralidade (Dias, 2000; Mello, 2006). E, quando a lei não legitima as relações do quotidiano, "o primeiro movimento é buscar frear a vida cotidiana, negando legitimidade das relações afetivas que já existem" (Uziel, 2009, p. 144).

\section{CONSIDERAÇÕES FINAIS}

O processo de adoção passou por transformações ao longo dos anos, já que, inicialmente, ela ocorria 
como forma de solucionar os anseios dos adotantes inférteis ou estéreis, porém com os avanços legislativos e a maior visibilidade social para a adoção, os interesses da criança foram priorizados. As mudanças no panorama da adoção se deram basicamente com criação de leis sob a influência dos paradigmas previstos no ECA e na Lei Nacional da Adoção, os quais visam o interesse da criança e do adolescente, a convivência familiar e comunitária, e o estímulo às adoções diferenciadas, como por exemplo, a de grupos de irmãos e de adolescentes.

Nesta pesquisa, os pares homoafetivos participantes não se mostraram rígidos ou conservadores em relação ao perfil da criança adotada, pois não foram indicaram perfis rígidos para a criança pretendida. Apenas um par feminino escolheu características da filha, que está no grupo não aceito pela maioria dos casais - maior de dois anos, afro descendente.

A falta de regulamentação jurídica foi percebida como um aspecto que dificulta a adoção por pares homoafetivos, tendo estes que optar pela adoção monoparental, deixando o(as) filho(as) desprotegido(as) dos benefícios materiais e afetivos por parte de um dos pais. Assim, faz-se necessária a formulação de uma lei que regulamente este tipo de adoção, para que os adotantes se sintam amparados em seus direitos de pais e os adotados se apropriem de seus direitos de filho.

Apesar da inexistência de uma regulamentação da adoção por pares homoafetivos, alguns magistrados têm criado jurisprudências favoráveis, com argumentações de que os homoafetivos estão tão aptos à adoção como os heteroafetivos. Pode-se observar melhor esse fato nos relatos das dificuldades encontradas pelos pares no início da convivência com o(s) filho(s), em que o amor, o carinho, e atendimento coerente às necessidades das crianças foram suficientes para a superação das adversidades.

Da mesma forma, a inserção da criança nos novos ambientes sociais (escola e natação) se deu de forma gradativa. À medida que a família se adaptava, as dificuldades eram solucionadas e os papéis de autoridade puderam ser exercidos com mais naturalidade dentro das relações afetivas.

No processo de adaptação familiar e estruturação dos vínculos entre a criança e o par homoparental, se encontra a equipe técnica com a função de auxiliar nas dificuldades vivenciadas pelas famílias. No entanto, percebe-se em alguns relatos que a equipe parecia despreparada para lidar com a homoafetividade dos postulantes à adoção, pois deixou transparecer aos entrevistados dúvidas e preconceitos, o que foi vivenciado como uma barreira social/institucional para essas famílias.

As questões referentes à constituição de famílias homoafetivas repercutiram também na execução desta pesquisa, pois não foram encontrados sujeitos em Sergipe. Tal dificuldade pareceu atrelada ao medo de não ser aceito nos cadastros para adoção, o que é reforçado pela omissão legislativa.

Diante desse cenário de preconceitos implícitos, percebe-se a necessidade de enfrentar as barreiras jurídicas, sociais, morais, bem como ressignificar os princípios e valores da família, trazendo aos diversos segmentos sociais informações sobre a união e/ou adoção homoafetiva, tomando como base estudos sistematizados que apontem as possibilidades dessas adoções como mais uma forma filiação.

\section{REFERÊNCIAS}

Academia Americana de Pediatria. (2002). Conparentalidad o adopción por segundo padre por padre del mismo sexo. Pediatrics, 109(3), 339-340.

Agência Senado. (2009). Lula sanciona nova lei nacional da adoção. G1. Retirado em 15 de agosto de 2009, de http://g1.globo.com/.../O,,MUL1252714-560100.html.

Almeida, M. R. (2003). A construção do afeto em branco e negro na adoção: limites e possibilidades de satisfação. 2003. 210 f. Dissertação (Mestrado em Psicologia) - Faculdade de Ciências e Letras de Assis. Universidade Estadual Paulista. Assis.

Amim, I. D. \& Menandro, P. R. M. (2007). Preferências por características do futuro filho adotivo manifestadas por pretendentes à adoção. Interação em Psicologia, 11(2), 241-252.

Andrade, R. P. de., Costa, R. N. do A. \& Rossetti-Ferreira, M. C. (2006). Significações de paternidade adotiva: um estudo de caso. Paidéia, 16(34), 241-252.

Badinter, E. (1985). Um amor conquistado: o mito do amor materno. Rio de Janeiro: Nova Fronteira.

Bailey, J. M., Bobrow, D., Wolf, M. \& Mikach, S. (1995). Sexual orientation: adult sons of gay fathers. Developmental Psychology, 31(1), 124-129.

Bee, H. (2003). A criança em desenvolvimento. $9^{\circ} \mathrm{ed}$. Porto Alegre: Artemed.

Berthoud, C. M. E. (2002). Re-significando a parentalidade: o desafio de ser pais. Taubaté: Cabral. 
Bowlby, J. (1982). Formação e rompimento de vínculos afetivos. In: Bowlby, J Formação e rompimento dos laços afetivos (Cabral, Alvaro) (pp. 119-150). São Paulo: Martins Fontes.

Brauer, J. F. (1993). Adoção de crianças: aspectos psicológicos. Pediatria moderna, 29(7), 1018-1020.

Brodzinsky, D. M., Smith, D. W. \& Brodzinsky, A. B. (1998). Children's adjustment to adoption developmental and clinical issues. Thousand Oaks: Sage.

Brooks, D., \& Goldberg, S. (2001). Gay and lesbian adoptive and foster care placements: can they meet the needs of waiting children? National Association of Social Workers, 46 (2), 147-157.

Cadastro Nacional de Adoção (2008). Adoção Brasil. Retirado em 02 de dezembro de 2010, de http://www.adocao brasil.com.br/faq005.asp.

Campos, N. M. V. \& Costa, L. F. (2004). A subjetividade presente no estudo psicosocial da adoção. Psicologia: Reflexão e Crítica, 17(1), 95-104.

Cassin, W. (2000). O psicólogo judiciário e a cultura da adoção: Limites, contradições e perspectivas. Dissertação de Mestrado não publicada, Curso de Pós-Graduação em Psicologia, Universidade de São Paulo, Ribeirão Preto, SP.

Cerveny, M. O. \& Berthoud, C. M. E. (Orgs) (2002). Visitando a família ao longo do ciclo vital. São Paulo: Casa do Psicólogo.

Costa, N. R. do A. \& Rossetti-Ferreira, M. C. (2007). Tornar-se pai e mãe em um processo de adoção tardia. $P$ sicologia: Reflexão e Crítica, 20(3), 425-434.

Dias, M. B. União homossexual: o preconceito e a justiça. Rio Grande do Sul: Livraria do Advogado, 2000.

Ebrahim, S. G. (2001). Adoção tardia: altruismo, maturidade e estabilidade emocional. Psicologia: Reflexão e Crítica, 14(1), 73-80.

Fernández, R. P., \& Vilar, A. A. (2004). Mental health contributions to the theory of the adoption by homosexual partners. Revista Internacional on-line, 3(2), 1-15.

Ferrari, J. L. (1999). Ser padres em el tercer milenio. Mendonza: Tintar Editorial.

Ferrari, J. L. (2011). Padres amado o deseado: la nueva relación entre padres e hijos. México: Trillas.

Fleck, A. C. \& Wagner, A. (2003). A mulher como a principal provedora do sustento econômico familiar. Psicologia em Estudo, (número especial), 51-58.

Freire, F. (2001). Abandono e adoção: contribuições para uma cultura da adoção III. Apresentação. Curitiba: Terra dos Homens, Vicentina.
Freixa, M. (1998). La família. In J. M. Redon (Ed.). La bolsa de los valores: materiales para una ética ciudadana. Barcelona: Ariel, 145-156.

Geertz, C. (2001). Nova luz sobre a antropologia. Rio de Janeiro: Jorge Zahar.

Golombok, S. \& Tasker, F. (1996). Do parents influence the sexual orientation of theirs children? Developmental Psychology, 32(1), 3-11.

Hine, C. (2000). Etnográfia Virtual. Londres: Sage Publications.

Mariano, F. N. \& Rossetti-Ferreira, M. C. (2008). Que perfil da família biológica e adotante, e da criança adotada revelam os processos judiciais? Psicologia: Reflexão e Crítica, 27(1), 11-19.

Martínez, N. Z. (2010). Crianza compartida. México: Trillas.

Matias, D. (2007). Psicologia e orientação sexual: realidades em transformação. Análise psicológica, l(XXV), 149-152.

Mello, L., (2006). Familiarismo (anti)homossexual e regulação da cidadania no Brasil. Estudos Feministas, 14(2), 497-508.

Mota, M. M., \& Vargas, M. M. (2010). Valores, crenças e rituais de classe média Aracajuana. Trabalho apresentado na $12^{\text {a }}$ SEMPESQ da Universidade Tiradentes. Aracaju.

Naranjo, C. J. G., Hernandez, J. M., Oliver, J. P., \& Chacón, F. (2004). Familias diversas, familias com derechos. Asatlas. Retirado em 13 de março de 2010, de http://www.asatlas.org

Patterson, C. J. (2006). Children of lesbian and gay parents. Current Direction in Psychological Science, 15(5), 241244.

Rossetti-Ferreira, M. C., Amorim, K., Silva, A. P. S. \& Carvalho, A. M. A. (Orgs). (2004). Rede de Significações e o estudo do desenvolvimento humano. Porto Alegre: Artmed.

Sarriera, J. C., Silva, M. A., Kabbas, C. P. \& Lópes, V. B. (2001). Formação de identidade ocupacional em adolescentes. Estudos de Psicologia, 6(1), 27-32.

Spengler, F. M. (2008). Sexualidade, conflitos de gênero e adoção: por um projeto parental baseado na igualdade e no afeto. Fazendo gênero 8 . Retirado em 31 de agosto de 2009 de http://www.fazendogenero8.ufsc.br/sts/ST50/Fa biana_Marion_Spengler_50.pdf

Turcatto, S. A. (2002). Repensando a maternidadelpaternidade pela via da adoção: um estudo sobre a família adotiva na atualidade. Dissertação de Mestrado, FCL, Universidade Estadual Paulista, Assis.

Uziel, A. P. (2007) Homossexualidade e adoção. Rio de Janeiro: Garamond. 
Uziel, A. P. (2009) Homossexualidades e formação familiar no Brasil contemporâneo Revista latino-americana de estúdios de família. v. 1, enero-diciembre, 104-115.

Vargas, M. M. (1998). Adoção tardia: da família sonhada à família possível. São Paulo: Casa do Psicólogo.

Vargas, M. M. (2006). A adoção de crianças maiores. In: Schettini Filho, L. \& Schetinni, S. S. (orgs.). Adoção os vários lados dessa história (pp. 147-172). Recife: Bagaço.

Venditti Jr, R. \& Santiago, V. (2008). Ludicidade, diversão e motivação como mediadores da aprendizagem infantil em natação: proposta para iniciação em atividades aquáticas com crianças de 3 a 6 anos. Revista Digital, 12(117), 1-7.
Weber, L. N. D. \& Kossobuski, L. H. M. (1993). Institucionalização e abandono de crianças no Paraná. Curitiba: Humanas.

Weber, L. N. D. (2003). Aspectos psicológicos da adoção. Curitiba: Juruá.

\section{Nota:}

1 Couvad, termo de origem francesa que significa o processo de mudanças físicas, psicológicas e afetivas que os homens de tribos sul-americanas apresentavam durante o processo gestacional e os primeiros dias de vida de seus filhos. 